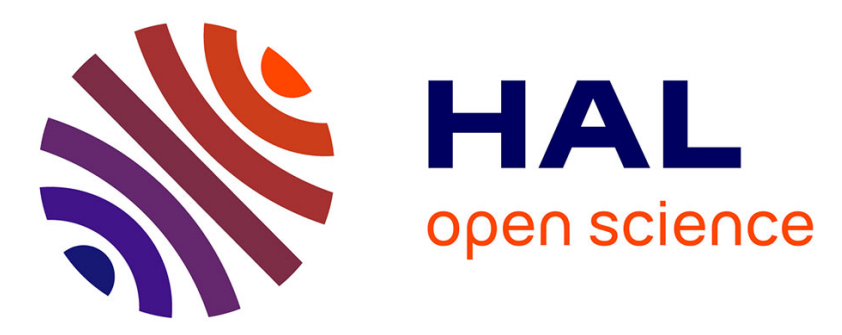

\title{
A Metalloenzyme-Like Catalytic System for the Chemoselective Oxidative Cross-Coupling of Primary Amines to Imines under Ambient Conditions
}

\author{
Martine Largeron, Maurice-Bernard Fleury
}

\section{> To cite this version:}

Martine Largeron, Maurice-Bernard Fleury. A Metalloenzyme-Like Catalytic System for the Chemoselective Oxidative Cross-Coupling of Primary Amines to Imines under Ambient Conditions. Chemistry - A European Journal, 2015, 21 (9), pp.3815-3820. 10.1002/chem.201405843 . hal-02384694

\author{
HAL Id: hal-02384694 \\ https://hal.science/hal-02384694
}

Submitted on 21 Nov 2020

HAL is a multi-disciplinary open access archive for the deposit and dissemination of scientific research documents, whether they are published or not. The documents may come from teaching and research institutions in France or abroad, or from public or private research centers.
L'archive ouverte pluridisciplinaire HAL, est destinée au dépôt et à la diffusion de documents scientifiques de niveau recherche, publiés ou non, émanant des établissements d'enseignement et de recherche français ou étrangers, des laboratoires publics ou privés. 


\section{A Metalloenzyme-Like Catalytic System for the Chemoselective Oxidative Cross-Coupling of Primary Amines to Imines under}

\section{Ambient Conditions}

\author{
Martine Largeron, ${ }^{*}$ and Maurice-Bernard Fleury
}

\begin{abstract}
The direct oxidative cross-coupling of primary amines is a challenging transformation as homocoupling is usually preferred. We report herein the chemoselective preparation of cross-coupled imines through the synergistic combination of low loadings of $\mathrm{Cu}^{\prime \prime}$ metal-catalyst and o-iminoquinone organocatalyst under ambient conditions. This homogeneous cooperative catalytic system has been inspired by the reaction of copper amine oxidases, a family of metalloenzymes with quinone organic cofactors that mediate the selective oxidation of primary amines to aldehydes. After optimization, the desired cross-coupled imines are obtained in high yields with broad substrate scope through a transamination process, that leads to the homocoupled imine intermediate, followed by dynamic transimination. The ability to carry out the reactions, at room temperature, with ambient air rather than molecular oxygen as the oxidant and equimolar amounts of each coupling partner, is particularly attractive from an environmentally viewpoint.
\end{abstract}

\section{Introduction}

Imines, commonly known as Schiff bases, represent a very important class of $\mathrm{N}$-containing intermediates widely utilized as electrophiles in many organic transformations such as reduction, addition, condensation and cyclization. They are also essential pharmacophores in numerous biologically active compounds. Imines have traditionally been prepared through condensation of amines with aldehydes or ketones, but new mild and practical catalytic methods ${ }^{[1]}$ including oxidative coupling of alcohols and amines ${ }^{[2]}$ together with oxidation of secondary amines ${ }^{[3]}$ have also been developed. For a long time, little attention had been given to the oxidation of primary amines probably due to poor product selectivity. ${ }^{[4]}$ The discovery of homogeneous and heterogeneous catalytic systems that operate effectively with molecular oxygen as the sole oxidant has contributed to revitalize interest in this area. ${ }^{[5]}$ Recently, non-noble transition-metal catalysis, ${ }^{[6]}$ metal-free catalysis, ${ }^{[7]}$ and photocatalysis ${ }^{[8]}$ have led to homocoupled imines in high yields and selectivity. However, save for a few exceptions, $\left.{ }^{[6,6 \mathrm{~d}]}\right]$

Dr. M. Largeron, Prof. Dr. M.- B. Fleury

UMR 8638 CNRS-Université Paris Descartes

Faculté de Pharmacie de Paris, Sorbonne Paris Cité

4, avenue de l'Observatoire, 75270 Paris Cedex 06 (France)

E-mail: martine.largeron@parisdescartes.fr

Supporting information for this article is given via a link at the end of the document. these catalytic systems require elevated temperature $\left(70^{\circ}-130^{\circ} \mathrm{C}\right)$ and/or oxygen pressure. In addition, the condensation of amines is not an efficient way to prepare cross-coupled imines due to the concomitant formation of self-coupling products. ${ }^{[6 a, 7 a, 9]}$ To the best of our knowledge, only two highly efficient and selective (>95\%) oxidative cross-coupling protocols for various amines have been reported to date, but they require high reaction temperatures $\left(100^{\circ} \mathrm{C}\right)$ together with oxygen pressure. ${ }^{[10]}$

The general interest in amine oxidation has also stimulated efforts to mimic the biological activity of metalloenzymes, ${ }^{[11]}$ in particular copper amine oxidases (CuAOs) that promote selective aerobic oxidation of primary amines to aldehydes in nature through the cooperation between a quinone-based cofactor (topaquinone) and copper. ${ }^{[12]}$ Recently, metalloenzyme-like catalytic systems have been developed for the aerobic oxidation of primary amines to imines under mild conditions. ${ }^{[13]}$ In particular, the topaquinone analog 5-tert-butyl-2-hydroxy-1,4-benzoquinone has been described as an efficient biomimetic organocatalyst for the chemoselective aerobic oxidative self-coupling of primary amines to imines, at room temperature, under 1 atm of molecular oxygen. The exclusive selectivity for primary benzylic amines allowed the preparation of various cross-coupled imines in high yields, from the oxidative condensation of benzylamine with anilines or with primary aliphatic amines. ${ }^{[13 b]}$

We have ourselves described a biomimetic homogeneous catalytic system for the aerobic oxidation of primary amines to imines, based on the synergistic combination of copper and a topaquinone-like organocatalyst $\mathbf{1}_{\text {ox }}$, first discovered from electrochemical investigations ${ }^{[14]}$ Low catalysts loadings (2 mol\% of $\mathbf{1}_{\text {red }}$ precursor of $\mathbf{1}_{\text {ox }}$ and $0.2 \mathrm{~mol} \%$ of $\mathrm{Cu}^{\prime}$ ) were sufficient to oxidize benzylic and aliphatic amines to self-coupled imines under ambient conditions. The oxidation process started with atmospheric oxygen and continued in a cascade-like manner by passing the oxidation potential of oxygen through the copper salt to the organic oiminoquinone mediator $\mathbf{1}_{\mathrm{ox}}$, that finally oxidized the amine substrate (Scheme 1).

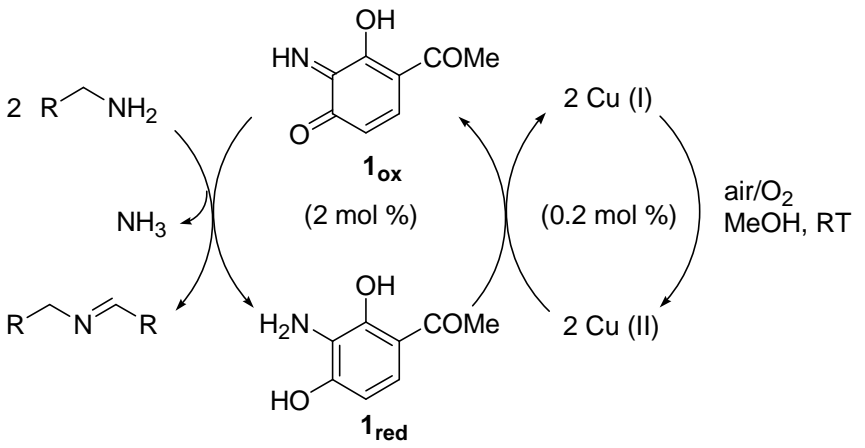

Scheme 1. Aerobic oxidation of primary amines to imines catalyzed by $\mathrm{Cu}^{\mathrm{l}} / \mathbf{1}_{\mathrm{ox}}$ cooperative system 
This catalytic process that combines two redox couples where the 0 iminoquinone organocatalyst $\mathbf{1}_{\mathrm{ox}}$ is the substrate-selective catalyst and the copper salt serves as an electron transfer mediator brings back other biomimetic catalytic systems that use transition metals as substrate-selective catalysts coupled with electron transfer mediators. ${ }^{[15]}$

Interestingly, the oxidative condensation of 4-methyl benzylamine with several aliphatic amines produced the corresponding cross-coupled imine in good yields, together with $\mathrm{N}$ (4-methylbenzyl)-1-( $p$-tolyl)methanimine derived from homo condensation as the minor product $(5-30 \%)$. This expedient investigation of the performance of our bioinspired catalytic system led to a preliminary communication. ${ }^{[16]}$ At this stage, only 4methylbenzylamine or benzylamine $e^{[9,10,13 b, d]}$ had been engaged in the oxidative cross-coupling with alkylating amines. So, the development of a more general method that would operate effectively with complete selectivity, under ambient conditions, would be highly desirable but still challenging.

In this full paper, we have tried to achieve exclusive formation of cross-coupling imines and to expand the substrate scope. Diverse benzylic amines including heterocyclic amines containing sulfur and oxygen atoms could be converted, with complete selectivity, into the corresponding cross-coupled imines in high yields. The synthesis of aliphatic imines was inherently more challenging because of their instability resulting from subsequent tautomerization to the enamine form that decomposed under ambient air. Although the crosscoupled aliphatic imine could be formed with complete selectivity as shown through monitoring the ${ }^{1} \mathrm{H}$ NMR spectrum, we were not able to isolate it as such. So, we decided to engage the generated alkylimine in situ in Diels-Alder reaction with the Danishefsky's diene to produce $\mathrm{N}$-alkylpyridin-4-one derivatives. Finally, all the results led us to revise the reaction pathway we had previously proposed for the oxidative cross-coupling of primary amines to imines. ${ }^{[16]}$

\section{Results and Discussion}

Choice of the optimal reaction conditions: First, we performed

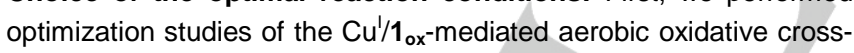
coupling process using 4-methylbenzylamine $\mathbf{2 a}$ and 1 ethylpropylamine $\mathbf{3 a}$ as the amine substrates. Only the copper source and solvent were varied, while the use of $o$-aminophenol $\mathbf{1}_{\text {red }}$ precursor of the o-iminoquinone cooperative organocatalyst $\mathbf{1}_{\text {ox }}$, room temperature and ambient air as the source of oxidant was retained throughout. As shown in Table 1, the initial oxidation state of the copper catalyst had not significant impact on the reaction efficiency (entries 1-5). The reaction progressed in all of the solvents used (entries 5-8), but, after 10h, complete conversion was observed only in $\mathrm{MeOH}$ likely because strong solvation of the 0 iminoquinone $\mathbf{1}_{\mathrm{ox}}$ by $\mathrm{MeOH}$ was required to enhance the electrophilicity of its quinonoid moiety, thereby favoring the nucleophilic attack of 4-methylbenzylamine $2 a^{[14]}$

Optimization of the reaction parameters showed that mixing 4methylbenzylamine $\mathbf{2} \mathbf{a}$ and 1 -ethylpropylamine $\mathbf{3 a}$ in the ratio $1: 1$ with $\mathrm{Cu}(\mathrm{OAc})_{2}(0.4 \mathrm{~mol} \%)$ and 0 -aminophenol $\mathbf{1}_{\text {red }}(4 \mathrm{~mol} \%)$, in $\mathrm{MeOH}$ under ambient conditions, afforded the desired cross-coupled product 4 a with $95 \%$ selectivity after $10 \mathrm{~h}$ (entry 5). In addition, exclusive formation of $\mathbf{4 a}$ could be attained when an additional aliquot of $o$-aminophenol $\mathbf{1}_{\text {red }}(1 \mathrm{~mol} \%)$ was introduced after $6 \mathrm{~h}$ which corresponded to $95 \%$ conversion. Probably, the in situ generated oiminoquinone organocatalyst $\mathbf{1}_{\text {ox }}$ slightly polymerized. Control studies revealed that copper catalyst and organocatalyst $\mathbf{1}_{\text {ox }}$ worked cooperatively to facilitate the aerobic oxidation of amines to imines under ambient conditions. In the absence of copper, the reaction proceeded very slowly owing to the spontaneous aerobic oxidation of $\mathbf{1}_{\text {red }}$ to $\mathbf{1}_{\text {ox }}$, whereas no reaction occurred at room temperature when copper salt was used as the sole catalyst.

Table 1. Optimization of the $\mathrm{Cu} / 1 / \mathbf{1}_{\text {ox }}$-catalyzed aerobic oxidative crosscoupling of 4-methylbenzylamine $2 \mathbf{a}$ with 1 -ethylpropylamine $3 \mathbf{a}^{[\mathrm{at}]}$

\begin{tabular}{lllll} 
& \\
\hline & & & \\
\hline
\end{tabular}

[a] The reactions were carried out using equimolar amounts of amines $2 \mathbf{a}$ and 3a on a $2.5 \mathrm{mmol}$ scale, in the presence of $4 \mathrm{~mol} \%$ of $\mathbf{1}_{\text {red }}$ and $0.4 \mathrm{~mol} \%$ of copper salt, in $10 \mathrm{~mL}$ of solvent, at room temperature, under ambient air for 10h. [b] Molar ratio based on the ${ }^{1} \mathrm{H}$ NMR spectrum of the crude product. [c] After $6 \mathrm{~h}$, an additional aliquot of $\mathbf{1}_{\text {red }}(1 \mathrm{~mol} \%)$ was added. CuMeSal : copper (I) 3-methylsalicylate.

Scope and functional group tolerance of $\mathrm{Cu}^{\prime \prime} / 1_{\mathrm{ox}}$-mediated oxidative cross-coupling of two primary amines: To explore potential applications of this method, the optimized reaction conditions (Table 1 , entry 5 ) were first applied to the catalytic oxidative cross-coupling of 4-methylbenzylamine 2a with diverse primary amines 3 (Table 2). Both branched and linear aliphatic amines (entries 1-6) could be efficiently coupled with 4methylbenzylamine $\mathbf{2 a}$ in high yields, with complete selectivity, 
except for $n$-hexylamine $\mathbf{3 e}$ and aminomethylcyclohexane $\mathbf{3 f}$ for which small amounts of homocoupled imines (4-5\%) were also isolated (entries 5, 6). 1-Phenylethan-1-amine $\mathbf{3 g}$ (entry 7) together with 2,3-dihydro- $1 \mathrm{H}$-inden-2-amine $\mathbf{3 h}$ (entry 8 ) reacted efficiently with $2 \mathrm{a}$ leading to cross-coupled imines that directly precipitated in the bulk solution. As has earlier been observed, ${ }^{[13 b]}$ anilines $\mathbf{3 i - k}$ (entries 9-11) were less reactive, but afforded cross-coupled imines with good levels of conversion after $48 \mathrm{~h}$, provided a second $2 \mathrm{~mol} \%$ portion of $o$-aminophenol $\mathbf{1}_{\text {red }}$ was added after $24 \mathrm{~h}$ (entries 9 and $10)$, with the exception of $p$-chloroaniline $\mathbf{3} \mathbf{k}$ for which the conversion could not exceed $60 \%$ (entry 11 ). Interesting, introduction of ether or alcohol groups (entries 12-14) allowed the synthesis of functionalized cross-coupled imines, especially without oxidation of the alcohol fragment (entry 14).

Table 2. $\mathrm{Cu}(\mathrm{OAc})_{2} / \mathbf{1}_{\mathrm{ox}}-$ catalyzed aerobic oxidative cross-coupling of 4methylbenzylamine $\mathbf{2 a}$ with diverse primary aliphatic and aromatic amines $3^{[a]}$

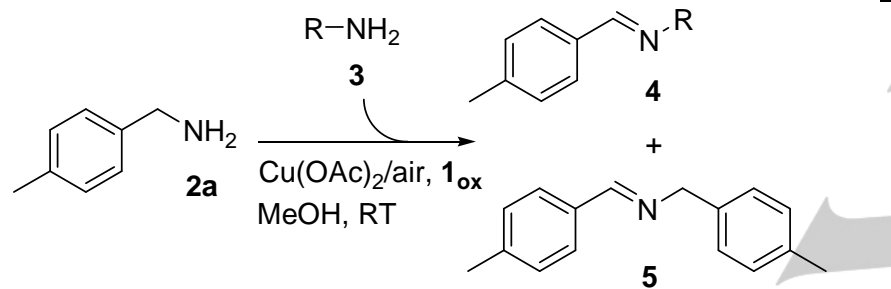

5

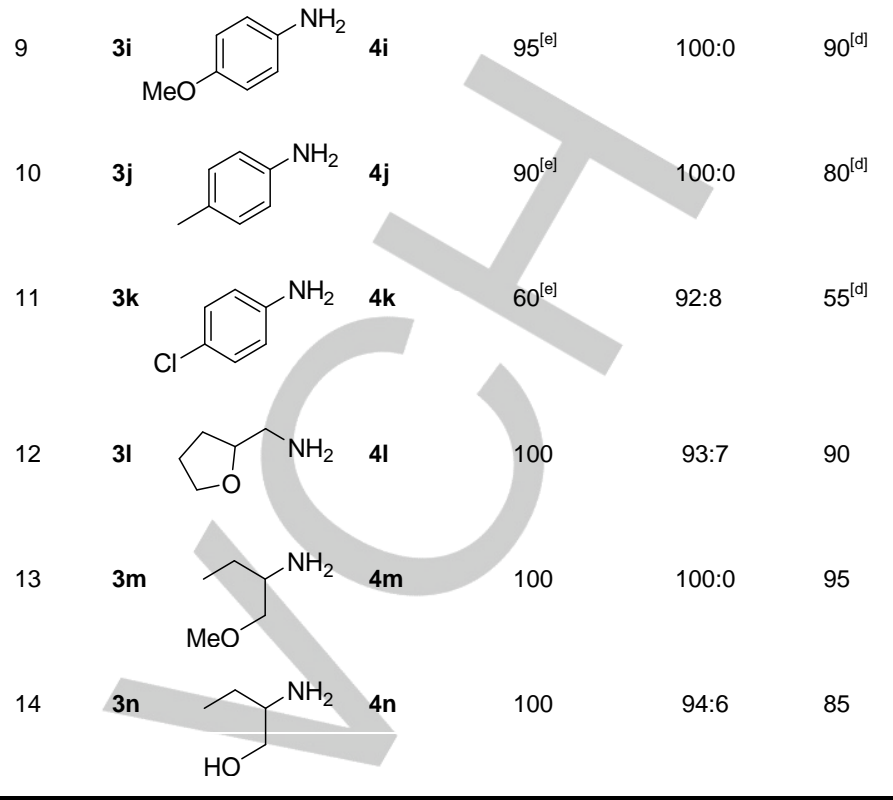

[a] The reactions were carried out using equimolar amounts of amines $\mathbf{2 a}$ and 3 on a $2.5 \mathrm{mmol}$ scale, in the presence of $5 \mathrm{~mol} \%$ of $\mathbf{1}_{\text {red }}(4 \mathrm{~mol} \%+1 \mathrm{~mol} \%$ added after $6 \mathrm{~h}$ ) and $0.4 \mathrm{~mol} \%$ of $\mathrm{Cu}(\mathrm{OAc})_{2}$, in $10 \mathrm{~mL}$ of methanol, at room temperature, under ambient air for $10 \mathrm{~h}$. [b] Molar ratio based on the ${ }^{1} \mathrm{H}$ NMR spectrum of the crude product. [c] Yields of the cross-coupled imine refer to the isolated unpurified product, which, unless otherwise stated, was pure by ${ }^{1} \mathrm{H}$ NMR spectroscopy (see the Supporting Information). [d] cross-coupling imine product directly precipitated in the bulk solution. [e] conversion after $48 \mathrm{~h}$, provided a second 2 mol\% portion of $o$-aminophenol $\mathbf{1}_{\text {red }}$ was added after $24 \mathrm{~h}$.

In a second series of experiments, diverse primary amine substrates 2 were screened in the presence of 1 -ethylpropylamine 3a (Table 3). High yields of cross-coupled imines were obtained from substituted benzylamines 2a-j regardless of the electronic character and the position of the substituents (entries 1-10). The free amino group of $p$-aminobenzylamine $\mathbf{2} \mathbf{g}$ did not affect the cross-coupling reaction although the yield slightly decreased (75\%, entry 7 ). Likewise, a sterically bulky group such as 1-naphthyl was well tolerated (entry 11). Furthermore, heterocyclic amines $\mathbf{2 l}$ and $\mathbf{2 m}$ containing sulfur and oxygen atoms could be cross-coupled with $\mathbf{3 a}$ in high yields with complete selectivity (entries 12 and 13).

Much more challenging, the possibility of expanding the reaction scope to the synthesis of scarcely stable aliphatic imines was also explored. The catalytic oxidative cross-coupling of aminomethylcyclopropane $\mathbf{6}$ and 4-methoxyaniline $\mathbf{3 i}$ was chosen as the example and monitored by ${ }^{1} \mathrm{H}$ NMR spectroscopy. In the reaction of equimolar amounts of both amines 6 and $\mathbf{3 i}$, the time course revealed the formation of only heterocoupled product 7 at early stages of the reaction. Although 1-cyclopropyl- $\mathrm{N}$-(4-methoxyphenyl) methanimine 7 could be observed through monitoring the ${ }^{1} \mathrm{H}$ NMR spectrum (see the Supporting Information), its instability with time did not permit to isolate it as such. Nevertheless, the mild conditions required for the generation of unstable cross-coupled aliphatic imine 7 proved to be useful for using it in situ as a dienophile in Diels-Alder reactions. After roughly $60 \%$ conversion of aminomethyl cyclopropane 6, the reaction mixture was mixed with Danishefsky's diene 8 to form the dihydro-4-pyridone derivative $\mathbf{9}$ in $45 \%$ isolated 
yield (Scheme 2). Similar acid-free tandem oxidative aza Diels-Alder reactions have been earlier reported for the synthesis of $\mathrm{N}$-aryl and $\mathrm{N}$-alkylbenzaldimines. ${ }^{[17]}$ Beside dihydro-4-pyridone $\mathbf{9}, \quad(Z)$ enaminone $\mathbf{1 0}$ was also isolated in $52 \%$ yield. The formation of $\mathbf{1 0}$ indicated that both 1-cyclopropyl- $\mathrm{N}$-(4-methoxyphenyl) methanimine 7 and Danishefsky's diene 8 hydrolyzed partially under our experimental conditions leading to benzaldehyde, 4-methoxyaniline 3i together with $(3 E)$-4-methoxybut-3-en-2-one. The latter further reacted with 4-methoxyaniline $\mathbf{3 i}$ to generate the $(Z)$-enaminone $\mathbf{1 0}$ as previously reported. ${ }^{[18]}$ As a proof of the partial hydrolysis of methanimine 7 , when the same reaction was performed using 4methylbenzylamine $\mathbf{2 a}$ as the amine substrate that was oxidized to stable benzaldimine $\mathbf{4} \mathbf{i}$, dihydro-4-pyridone $\mathbf{1 1}$ was isolated in $80 \%$ yield at the exclusion of (Z)-enaminone by-product 10 (Scheme 2 ).

Table 3. $\mathrm{Cu}(\mathrm{OAc})_{2} / \mathbf{1}_{\text {ox }}$-catalyzed aerobic oxidative cross-coupling of diverse primary amines 2 with 1 -ethylpropylamine $3 \mathrm{a}^{[\mathrm{a}]}$

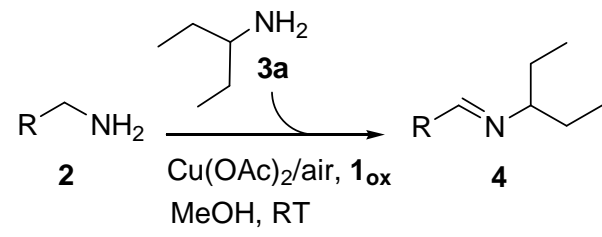

\begin{tabular}{|c|c|c|c|c|}
\hline Entry & Amine & Substrate 2 & $\begin{array}{l}\text { Imine } \\
\text { Product } 4\end{array}$ & $\begin{array}{c}\text { Conversion } \\
(\%)\end{array}$ \\
\hline 1 & $2 a$ & & $4 a$ & 100 \\
\hline
\end{tabular}

2
$2 b$<smiles>NCc1ccccc1</smiles>

3

2c<smiles>CC(C)(C)c1ccc(CN)cc1</smiles>

2d

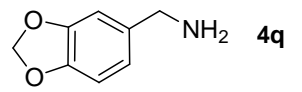

5

$2 e$<smiles>COc1ccc(CN)cc1</smiles>

$4 p$
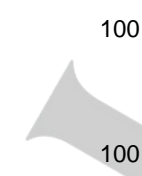

100

100

100

92

95

8

$2 h$<smiles>NCc1ccc(N)cc1</smiles>

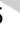

75<smiles>NCc1ccc(C(F)(F)F)cc1</smiles>

100

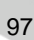<smiles>[C+]CNCc1ccc(OC)cc1</smiles>

10

2j<smiles>NCc1ccc(Cl)cc1Cl</smiles>

100

96

11

2k<smiles>NCc1ccc2ccccc2c1</smiles>

$4 x$

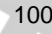

12

2I

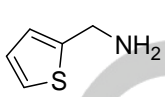

$4 y$

100

94

13

$4 z$

100

95 [a] The reactions were carried out using equimolar amounts of amines 2 and 3a on a $2.5 \mathrm{mmol}$ scale, in the presence of $5 \mathrm{~mol} \%$ of $\mathbf{1}_{\text {red }}(4 \mathrm{~mol} \%+1 \mathrm{~mol} \%$ added after $6 \mathrm{~h}$ ) and $0.4 \mathrm{~mol} \%$ of $\mathrm{Cu}(\mathrm{OAc})_{2}$, in $10 \mathrm{~mL}$ of methanol, at room temperature, under ambient air for 10h. [b] Yields of the cross-coupled imine refer to the isolated unpurified product, which, unless otherwise stated, was pure by ${ }^{1} \mathrm{H}$ NMR spectroscopy (see the Supporting Information).

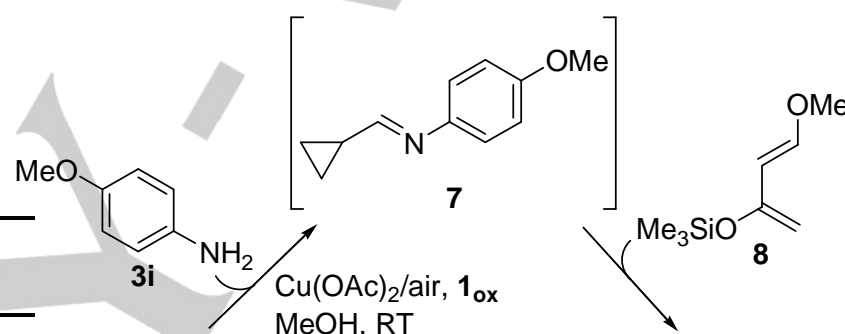
$\mathrm{OMe}$<smiles>COc1ccc(N/C=C/C(C)=O)cc1</smiles>

$10(52 \%)$

$9(45 \%)$

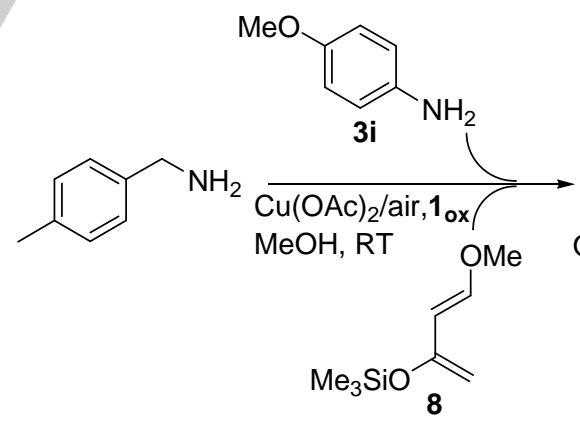<smiles>COc1ccc(N2C=CC(=O)CC2c2ccc(C)cc2)cc1</smiles>

$11(80 \%)$

Scheme 2. Tandem oxidative aza Diels-Alder reaction for the synthesis of dihydro-4-pyridones

Mechanistic considerations: On the basis of only one example of cross-coupling reactions, we had previously proposed that both homo- and cross-coupling products would be produced competitively through the ionic transamination mechanism earlier described. ${ }^{[16]}$ Our present investigation into the substrate scope of the $\mathrm{Cu}^{\prime \prime} / \mathbf{1}_{\text {ox }}$ - 
mediated cross-coupling of two primary amines led us to revise our original proposals to the one depicted in Scheme 3. Indeed, in almost all of the cases, the real-time monitoring of the cross-coupling reactions by ${ }^{1} \mathrm{H}$ NMR spectroscopy indicated that the homocoupling product was initially formed and accumulated at early stages of the reaction. After roughly $30 \mathrm{~min}$, the homocoupled imine gradually turned to the cross-coupling product that finally became the exclusive product after ten hours. Of particular note, only the reaction of 4-methylbenzylamine $2 \mathrm{a}$ with $n$-hexylamine $\mathbf{3 e}$ (Table 2, entry 5) or aminomethylcyclohexane $\mathbf{3 f}$ (Table 2, entry 6) revealed the simultaneous formation of homo- and cross-coupling products (4e or $\mathbf{4 f}$ ) from the outset of the reaction, but with a preference for the homocoupling product 5 . These observations indicated that the homocoupling product was first generated as the sole imine product through the transamination mechanism earlier reported. ${ }^{[14,16]}$ This was further alkylated by the second primary amine $\mathrm{R}^{\prime}-\mathrm{NH}_{2}$ through a transimination process ${ }^{[19]}$ to give the cross-coupling product whose formation could be driven by continuous oxidation of the extruded primary amine $\mathrm{R}-\mathrm{CH}_{2}-\mathrm{NH}_{2}$ (self-sorting step) as shown in Scheme 3 . As a consequence, just one equivalent of both primary amines was sufficient to achieve exclusive formation of the cross-coupling imine product. This oxidative strategy known as "oxidative self-sorting" has previously been exploited to obtain thermodynamically disfavored products. ${ }^{[13 b, 20]}$ We have further validated our mechanistic process by subjecting the isolated homocoupled imine $\mathbf{5}$ with two equivalents of 1-ethylpropylamine $\mathbf{3 a}$ under the standard conditions (Table 1, entry 5). Then, full conversion of the homocoupled imine 5 into the crosscoupling imine $\mathbf{4 a}$ was observed after ten hours providing support for the two-step mechanism.

The synthesis of cross-coupled aliphatic imines was found to be troublesome because of their instability. The main problem associated with these imines is related to the formation of the tautomeric enamine form which decomposed under ambient air. ${ }^{[21]}$ Nevertheless, the fact that aliphatic imines can be engaged in situ for further reactions leading to $\mathrm{N}$-alkylpyridin-4-one derivatives demonstrates that aliphatic amines are well oxidized to imines under our experimental conditions as previously reported. ${ }^{[16]}$ Whereas transition-metal-catalyzed oxidations to dehydrogenate aliphatic amines to imines require vigorous reaction conditions, the synergistic action of our bioinspired homogeneous cooperative catalyst lowers the activation energy enabling high reactivity that neither catalyst can accomplish alone.

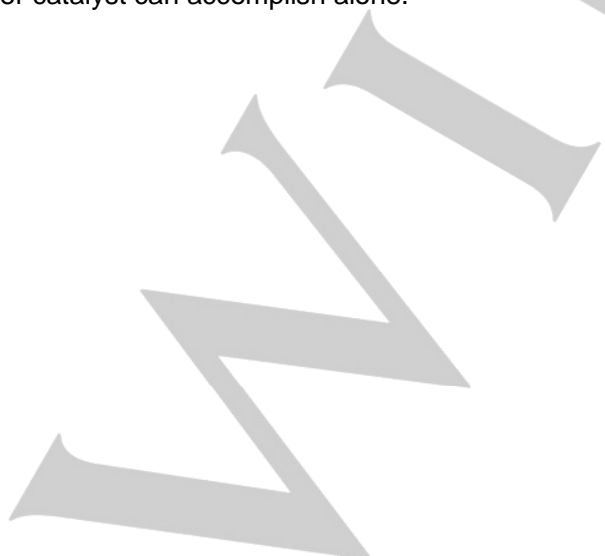

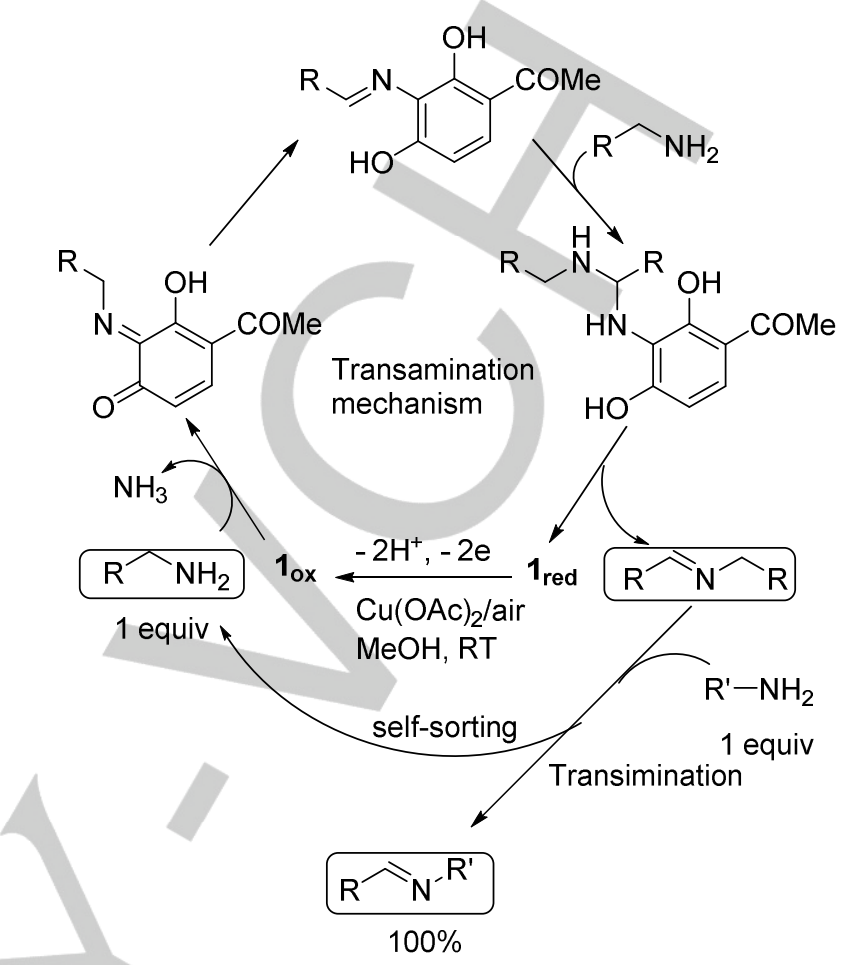

Scheme 3. Proposed overall two-step mechanism for the $\mathrm{Cu}(\mathrm{OAc})_{2} / \mathbf{1}_{\text {ox }}$ mediated cross-coupling of primary amines

\section{Conclusions}

New insights into the scope and mechanism of the bioinspired $\mathrm{Cu}^{\mathrm{II}} / \mathbf{1}_{\mathrm{ox}}$-catalyzed aerobic oxidative cross-coupling of primary amines to imines have been delineated. Low loadings of biocompatible $\mathrm{Cu}^{\prime \prime}$ metal catalyst and topaquinone-like organocatalyst $1_{\text {ox }}$ were sufficient to activate the $\alpha-\mathrm{C}-\mathrm{H}$ bond of various primary amines, which were converted to cross-coupled imines through a transamination process, that leads to the homocoupled imine intermediate, followed by dynamic transimination. This atom-economical process, that proceeds at room temperature, under ambient air, with equimolar amount of each coupling partners and tolerates diverse functional groups, generates with unprecedented selectivity cross-coupled imines which have been previously shown to have broad use in organic synthesis. The mild reaction conditions used in this work should be particularly favorable for using the unstable alkylimines in situ for further reactions.

\section{Experimental Section}

General considerations: ${ }^{1} \mathrm{H}$ NMR and $1 \mathrm{D}$ proton decoupled ${ }^{13} \mathrm{C}$ NMR spectra were recorded in $\mathrm{CDCl}_{3}$ on a Brucker AC-300 
spectrometer operating at $300 \mathrm{MHz}$ and $75 \mathrm{MHz}$, respectively. Chemical shifts $\delta$ are given in ppm relative to TMS and coupling constants $J$, in hertz. The measurements were carried out using the standard pulse-sequences. The carbon type (methyl, methylene, methine, or quaternary) was determined by DEPT experiments. Mass spectra were recorded on a ZQ 2000 Waters spectrometer, equipped with the positive electrospray mode (ES+). Chemicals were commercial products of the highest available purity and were used as supplied. Reduced catalyst $\mathbf{1}_{\text {red }}$ was synthesized in two steps from commercially available 2-nitroresorcinol. ${ }^{[2]}$

General experimental procedure for $\mathrm{Cu}^{\prime \prime} / 1_{\text {ox }}$-catalyzed aerobic oxidative cross-coupling of two primary amines. Equimolar amounts of 4-methylbenzylamine 2a $(2.5 \mathrm{mmol})$ and 1ethylpropylamine $3 \mathrm{a}(2.5 \mathrm{mmol})$, reduced organocatalyst $\mathbf{1}_{\text {red }}(0.1$ $\mathrm{mmol}, 4 \mathrm{~mol} \%)$, and copper (II) acetate $(0.01 \mathrm{mmol}, 0.4 \mathrm{~mol} \%)$ were mixed in methanol $(10 \mathrm{~mL})$ in an air atmosphere. The reaction mixture was stirred at room temperature for six hours. Then, an additional aliquot of $0.025 \mathrm{mmol}$ of $\mathbf{1}_{\text {red }}(1 \mathrm{~mol} \%)$ was introduced in the reaction mixture and the reaction was pursued during roughly four hours. The progress of the reaction was monitored by ${ }^{1} \mathrm{H}$ NMR spectroscopy. After completion of the reaction, the solvent was evaporated at room temperature to give the cross-coupling imine product $4 \mathrm{a}$ in $97 \%$ yield as an almost pure product as confirmed by ${ }^{1} \mathrm{H}$ and ${ }^{13} \mathrm{C}$ NMR spectroscopy (See the Supporting Information). Imine 4a: ${ }^{1} \mathrm{H}$ NMR $\left(300 \mathrm{MHz}, \mathrm{CDCl}_{3}, 25^{\circ} \mathrm{C}\right.$, TMS): $\delta=0.88$ (t, $\mathrm{J}=8$ $\left.\mathrm{Hz}, 6 \mathrm{H}, 2 \times \mathrm{CH}_{3}\right), 1.70\left(\mathrm{~m}, 4 \mathrm{H}, 2 \times \mathrm{CH}_{2}\right), 2.43\left(\mathrm{~s}, 3 \mathrm{H}, \mathrm{CH}_{3}\right), 2.91(\mathrm{~m}$, $1 \mathrm{H}, \mathrm{CH}), 7.25(\mathrm{~d}, J=7 \mathrm{~Hz}, 1 \mathrm{H}, 2 \times \mathrm{CH}, \mathrm{Ar}), 7.68(\mathrm{~d}, J=7 \mathrm{~Hz}, 1 \mathrm{H}, 2$ $\times \mathrm{CH}, \mathrm{Ar}), 8.24(\mathrm{~s}, 1 \mathrm{H}, \mathrm{CH}=\mathrm{N}) ;{ }^{13} \mathrm{C} \mathrm{NMR}\left(75 \mathrm{MHz}, \mathrm{CDCl}_{3}, 25^{\circ} \mathrm{C}\right.$, TMS): $\delta=11.1\left(2 \times \mathrm{CH}_{3}\right), 21.5\left(\mathrm{CH}_{3}\right), 28.9\left(2 \times \mathrm{CH}_{2}\right), 75.2(\mathrm{CH})$, $128.1(2 \times \mathrm{CH}, \mathrm{Ar}), 129.3(2 \times \mathrm{CH}, \mathrm{Ar}), 133.8(\mathrm{Cq}), 140.5(\mathrm{Cq}), 159.4$ $(\mathrm{CH}=\mathrm{N}) ; \mathrm{MS}(\mathrm{ES}+): \mathrm{m} / \mathrm{z}=190\left[\mathrm{MH}^{+}\right]$.

The above procedure is generally representative for all the products shown in Tables 2 and 3. Any deviations from this protocol are specified in the footnotes of the tables.

Representative procedure for $\mathrm{Cu} / 1 / 1_{\text {ox }}$-catalyzed aerobic oxidative synthesis of dihydro-4-pyridones derivatives. 1Cyclopropyl- $N$-(4-methoxyphenyl)methanimine 7 was prepared in situ by mixing equimolar amounts of aminomethylcyclopropane 6 $(1.25 \mathrm{mmol})$ and 4-methoxyaniline $\mathbf{3 i}(1.25 \mathrm{mmol})$, reduced organocatalyst $\mathbf{1}_{\text {red }}(0.05 \mathrm{mmol}, 4 \mathrm{~mol} \%)$, and copper (II) acetate (0.005 mmol, $0.4 \mathrm{~mol} \%)$ in methanol $(5 \mathrm{~mL})$ under ambient conditions for six hours. Then, an additional aliquot of $0.0125 \mathrm{mmol}$ of $\mathbf{1}_{\text {red }}(1 \mathrm{~mol} \%$ ) was introduced in the reaction mixture and the reaction was pursued during four hours. After roughly $60 \%$ conversion of aminomethylcyclopropane 6 into the cross-coupling imine product 7 (see the NMR spectrum in the Supporting Information), $2 \mathrm{~mL}$ of the resulting solution (that corresponds roughly to $0.3 \mathrm{mmol}$ of 7$)$ was taken and Danishefsky's diene $8(0.6 \mathrm{mmol}, 2$ equiv) was added dropwise in $30 \mathrm{~min}$. After stirring for 1 hour at room temperature, another equiv of Danishefsky's diene 8 (0.3 $\mathrm{mmol}$ ) was added dropwise in $15 \mathrm{~min}$ to the reaction mixture which was stirred for $2 \mathrm{~h}$ at room temperature. The reaction mixture was then quenched with $2 \mathrm{~mL}$ of $1.0 \mathrm{M} \mathrm{HCl}$. The product was extracted with diethyl ether and the solvent was evaporated under reduced pressure. The crude material was purified by column chromatography with dichloromethane/ethyl acetate $(4: 1 \mathrm{v} / \mathrm{v})$ as the eluent leading to dihydro-4-pyridone 9 in $45 \%$ yield together with (Z)enaminone 10 in $52 \%$ yield.

Dihydro-4-pyridone $9:{ }^{1} \mathrm{H}$ NMR $\left(300 \mathrm{MHz}, \mathrm{CDCl}_{3}, 25^{\circ} \mathrm{C}, \mathrm{TMS}\right): \delta=$ $0.00\left(\mathrm{~m}, 2 \mathrm{H}, \mathrm{CH}_{2}\right), 0.40\left(\mathrm{~m}, 2 \mathrm{H}, \mathrm{CH}_{2}\right), 1.37(\mathrm{~m}, 1 \mathrm{H}, \mathrm{CH}), 2.62$ (dd, $J$ $=16 \mathrm{~Hz}, J=4 \mathrm{~Hz}, 1 \mathrm{H}, \mathrm{CH}$ ), 2.98 (dd, $J=16 \mathrm{~Hz}, J=6.7 \mathrm{~Hz}, 1 \mathrm{H}, \mathrm{CH}$ ), $3.24(\mathrm{~m}, 1 \mathrm{H}, \mathrm{CH}), 3.85\left(\mathrm{~s}, 3 \mathrm{H}, \mathrm{CH}_{3}\right), 5.16(\mathrm{~d}, \mathrm{~J}=7.6 \mathrm{~Hz}, 1 \mathrm{H}, \mathrm{CH})$, $6.93(\mathrm{~d}, J=8.9 \mathrm{~Hz}, 2 \mathrm{H}, 2 \times \mathrm{CH}, \mathrm{Ar}), 7.16(\mathrm{~d}, J=8.9 \mathrm{~Hz}, 2 \mathrm{H}, 2 \times \mathrm{CH}$, Ar), $7.27(\mathrm{~d}, J=7.6 \mathrm{~Hz}, 1 \mathrm{H}, \mathrm{CH}), ;{ }^{13} \mathrm{C} \mathrm{NMR}\left(75 \mathrm{MHz}, \mathrm{CDCl}_{3}, 25^{\circ} \mathrm{C}\right.$, TMS): $\delta=1.7\left(\mathrm{CH}_{2}\right), 5.6\left(\mathrm{CH}_{2}\right), 12.1(\mathrm{CH}), 41.6\left(\mathrm{CH}_{2}\right), 55.5\left(\mathrm{CH}_{3}\right)$, $65.4(\mathrm{CH}), 99.6(\mathrm{CH}=), 114.6(2 \times \mathrm{CH}, \mathrm{Ar}), 125.2(2 \times \mathrm{CH}, \mathrm{Ar}), 138.6$ (Cq), $150.7(\mathrm{CH}=), 157.8(\mathrm{Cq}), 191.5(\mathrm{Cq}, \mathrm{C}=\mathrm{O})$; $\mathrm{MS}(\mathrm{ES}+): \mathrm{m} / \mathrm{z}=$ $244\left[\mathrm{MH}^{+}\right]$; elemental analysis cacld (\%) for $\mathrm{C}_{15} \mathrm{H}_{17} \mathrm{NO}_{2}: \mathrm{C} 74.07, \mathrm{H}$ 6.99, N 5.76; found C 73.96, H 7.10, N 5.74.

(Z)-enaminone $10:{ }^{1} \mathrm{H} \mathrm{NMR}$ (300 MHz, $\left.\mathrm{CDCl}_{3}, 25^{\circ} \mathrm{C}, \mathrm{TMS}\right): \delta=2.18$ (s, $\left.3 \mathrm{H}, \mathrm{CH}_{3}\right), 3.82\left(\mathrm{~s}, 3 \mathrm{H}, \mathrm{CH}_{3}\right), 5.30(\mathrm{~d}, J=7.6 \mathrm{~Hz}, 1 \mathrm{H}, \mathrm{CH}), 6.93$ (d, $J=9.0 \mathrm{~Hz}, 2 \mathrm{H}, 2 \times \mathrm{CH}, \mathrm{Ar}), 7.16(\mathrm{~d}, J=9.0 \mathrm{~Hz}, 2 \mathrm{H}, 2 \times \mathrm{CH}, \mathrm{Ar})$, $7.20(\mathrm{~m}, 1 \mathrm{H}, \mathrm{CH}), 11.65$ (broad d, $1 \mathrm{H}, \mathrm{NH}, \mathrm{D}_{2} \mathrm{O}$ exchanged); ${ }^{13} \mathrm{C}$ $\operatorname{NMR}\left(75 \mathrm{MHz}, \mathrm{CDCl}_{3}, 25^{\circ} \mathrm{C}, \mathrm{TMS}\right): \delta=29.4\left(\mathrm{CH}_{3}\right)$ ), $55.6\left(\mathrm{CH}_{3}\right)$, $96.6(\mathrm{CH}=), 114.9(2 \times \mathrm{CH}, \mathrm{Ar}), 117.7(2 \times \mathrm{CH}, \mathrm{Ar}), 134.0(\mathrm{Cq})$, 144.1 $(\mathrm{CH}=), 156.1(\mathrm{Cq}), 198.4(\mathrm{Cq}, \mathrm{C}=\mathrm{O}) .{ }^{1} \mathrm{H}$ and ${ }^{13} \mathrm{C}$ NMR spectral data are in agreement with those previously reported in the literature. ${ }^{[23]}$

\section{Acknowledgements}

The authors would like to thank ADRAPHARM (Association pour le Développement de la Recherche Appliquée à la Pharmacologie) for financial support of this work.

Keywords: homogeneous catalysis $\cdot$ cross-coupling $\bullet$ primary amines $\cdot$ oxidation $\cdot$ cycloaddition

[1] For recent reviews, see: a) R. D. Patil, S. Adimurthy, Asian J. Org. Chem. 2013, 2, 726-744; b) R. J. Angelici, Catal. Sci. Technol. 2013, 3, 279-296; c) W. Qing, S. Long, M. Panunzio, S. Biondi, Molecules 2013, 18, 12264-12289; d) B. L. Ryland, S. S. Stahl, Angew. Chem. 2014, 126, 8968-8934; Angew. Chem. Int. Ed. 2014, 53, 8824-8838.

[2] For selected recent examples, see: a) J. -F. Soulé, H. Miyamura, S. Kobayashi, Chem. Commun. 2013, 49, 355-357; b) B. Chen, J. Li, W. Dai, L. Wang, S. Gao, Green Chem. 2014, 16, 3328-3334; c) L. Han, P. Xing, B. Jiang, Org. Lett. 2014, 16, 3428-3431; d) M. Guan, C. Wang, J. Zhang, Y. Zhao, RSC Adv. 2014, 4, 48777-48782; e) M. Tamura, K. Tomishige, Angew. Chem. Int. Ed. 2014, DOI: 10.1002/anie.201409601.

[3] For selected recent examples, see: a) J. S. M. Samec, A. H. Ell, J. E. Bäckvall, Chem. Eur. J. 2005, 11, 2327-2334; b) B. Zhu, R. J. Angelici, Chem. Commun. 2007, 2157-2159; c) A. E. Wendlandt, S. S. Stahl, J. Am. Chem. Soc. 2014, 136, 506-512; d) A. E. Wendlandt, S. S. Stahl, J. Am. Chem. Soc. 2014, 136, 11910-11913.

[4] For a recent review, see: M. T. Schümperli, C. Hammond, I. Hermans, ACS Catal. 2012, 2, 1108-1117. 
[5] For a recent review, see: M. Largeron, Eur. J. Org. Chem. 2013, 2013, 5225-5235.

[6] For selected recent examples, see: a) R. D. Patil, S. Adimurthy, Adv. Synth. Catal. 2011, 353, 1695-1700; b) Z. Hu, F. M. Kerton, Org. Biomol. Chem. 2012, 10, 1618-1624; c) R. D. Patil, S. Adimurthy, RSC Adv. 2012, 2, 5119-5122; d) B. Huang, H. Tian, S. Lin, M. Xie, X. Yu, Q. Xu, Tetrahedron Lett. 2013, 54, 2861-2864; e) E. Zhang, H. Tian, S. Xu, S. Yu, Q. Xu, Org. Lett. 2013, 15, 2704-2707; f) H. Gu, X. Cao, S. Lu, J. Wang, Chem. Commun. 2014, 50, 5637-5640; g) S. Zhao, C. Liu, Y Guo, J.-C. Xiao, Q.-Y. Chen, J. Org. Chem. 2014, 79, 8926-8931.

[7] For selected recent examples, see: a) H. Huang, J. Huang, Y.-M. Liu, H.-Y. He, Y. Cao, K.-N. Fan, Green Chem. 2012, 14, 930-934; b) C. Su M. Acik, K. Takai, J. Lu, S.-J. Hao, Y. Zheng, P. Wu, Q. Bao, T. Enoki, Y.-J. Chabal, K. P. Loh, Nat. Commun. 2012, 3, 1298-1306; c) L. Liu, Z. Wang, X. Fu, C.-H. Yan, Org. Lett. 2012, 14, 5692-5695; d) H. Wang, X. Zheng, H. Chen, K. Yan, Z. Zhu, S. Yang, Chem. Commun. 2014, 50, 7517-7520.

[8] For a recent review, see: a) X. Lang, X. Chen, J. Zhao, Chem. Soc Rev. 2014, 43, 473-486. See also: b) J. H. Park, K. C. Ko, E. Kim, N. Park, J. H. Ko, D. H. Ryu, T. K. Ahn, J. Y. Lee, S. U. Son, Org. Lett. 2012, 14, 5502-5505; c) X. Lang, W. Ma, Y. Zhao, C. Chen, H. Ji, J. Zhao, Chem. Eur. J. 2012, 18, 2624-2631; d) S. -I. Naya, K. Kimura, H. Tada, ACS Catal. 2013, 3, 10-13; e) N. Li, X. Lang, W. Ma, H. Ji, C. Chen, J. Zhao, Chem. Commun. 2013, 49, 5034-5036; f) W. Zhao, C. Liu, L. Cao, X. Yin, H. Xu, B. Zhang, RSC Adv. 2013, 3, 22944-22948 g) X.-J. Yang, B. Chen, X.-B. Li, L.-Q. Zheng, L.-Z. Wu, C.-H. Tung Chem. Commun. 2014, 50, 6664-6667; h) L. Ye, Z. Li, ChemCatChem, 2014, 6, 2540-2543; i) B. Yuan, R. Chong, B. Zhang, J. Liu, C. Li, Chem. Commun. 2014, 50, 15593-15596. j) D. Sun, L. Ye, Z. Li, Appl. Catal. B: Environ. 2015, 164, 428-432.

[9] a) K. N. Tayade, M. Mishra, J. Mol. Catal. A - Chem. 2014, 382, 114 125 ; b) A. Monopoli, P. Cotugno, F. lannone, F. Ciminale, M. M. Dell'Anna, P. Mastrorilli, A. Nacci, Eur. J. Org. Chem. 2014, 2014 5925-5931.

[10] a) A. Grirrane, A. Corma, H. Garcia, J. Catal. 2009, 264, 138-144 ; b) X. Qiu, C. Len, R. Luque, Y. Li, ChemSusChem 2014, 7, 1684-1688.

[11] a) S.-I. Murahashi, D. Zhang, Chem. Soc. Rev. 2008, 37, 1490-1501; b) L. Que Jr; W. B. Tolman, Nature 2008, 455, 333-340.

[12] a) M. Mure, S.A. Mills, J.P. Klinman, Biochemistry 2002, 41, 9269 9278; b) M. Mure, Acc. Chem. Res. 2004, 37, 131-139.

[13] For a recent perspective, see: a) M. Largeron, M.-B. Fleury, Science, 2013, 339, 43-44. See also: b) A.E. Wendland, S. S. Stahl, Org. Lett. 2012, 14, 2850-2853; c) H. Yuan, W.-J. Yoo, H. Miyamura, S. Kobayashi, J. Am. Chem. Soc. 2012, 134, 13970-13973; d) D. V. Jawale, E. Gravel, E. Villemin, N. Shah, V. Geertsen, I. N. N. Namboothiri, E. Doris, Chem. Commun., 2014, 50, 15251-15254.

[14] M. Largeron, A. Chiaroni, M.-B. Fleury, Chem. Eur. J. 2008, 14, 9961003.

[15] For a review, see: J. Piera, J.-E. Bäckvall, Angew. Chem. 2008, 120 3558-3576; Angew. Chem. Int. Ed. 2008, 47, 3506-3523.

[16] M. Largeron, M.-B. Fleury, Angew. Chem. 2012, 124, 5505-5508; Angew. Chem. Int. Ed. 2012, 51, 5409-5412.

[17] For selected examples see: a) Y. Yuan, X. Li, K. Ding, Org. Lett. 2002, 4, 3309-3311; b) C. Loncaric, K. Manabe, S. Kobayashi, Chem. Commun. 2003, 574-575; c) L. Liu, S. Zhang, X. Fu, C.-H. Yan, Chem Commun. 2011, 47, 10148-10150.

[18] F. Bellezza, A. Cipiciani, U. Costantino, F. Fringuelli, M. Orrù, O. Piermatti, F. Pizzo, Catal. Today 2010, 152, 61-65

[19] For a recent review, see: a) M. Ciaccia, S. Di Stefano, Org. Biomol. Chem. 2015, DOI: 10.1039/C4OB02110j. See also: b) M. Ciaccia, R. Cacciapaglia, P. Mencarelli, L. Mandolini, S. Di Stefano, Chem. Sci. 2013, 4, 2253-2261 ; c) M. Ciaccia, S. Pilati, R. Cacciapaglia, L. Mandolini, S. Di Stefano, Org. Biomol. Chem. 2014, 12, 3282-3287.
[20] For a review, see: a) M. E. Belowich, J. F. Stoddart, Chem. Soc. Rev. 2012, 41, 2003-2024. See also: b) S. M. Landge, V. Atanassova, M. Thimmaiah, B. Török, Tetrahedron Lett. 2007, 48, 5161-6164.

[21] S. Morales, F. G. Garcia Ruano, M. B. Cid, J. Am. Chem. Soc. 2014, 136, 1082-1089.

[22] M. Largeron, A. Chiaroni, M.-B. Fleury, J. Org. Chem. 2006, 71, 63746381.

[23] J.-C. Zhuo, Magn. Reson. Chem. 1997, 35, 21-29

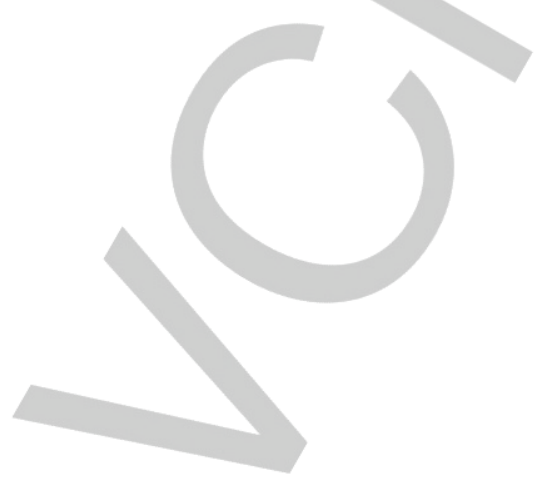


Entry for the Table of Contents (Please choose one layout)

Layout 2:

\section{FULL PAPER}

$$
\begin{aligned}
& \underset{1 \text { equiv }}{\mathrm{RH}_{2}} \widehat{\mathrm{NH}}_{1 \text { equiv }} \stackrel{\mathrm{Cu}(\mathrm{OAc})_{2}(0.4 \mathrm{~mol} \%) / \mathbf{1}_{\text {ox }}}{\text { ambient air, } \mathrm{MeOH}, \mathrm{RT}} \underset{100 \% \text { selectivity }}{\longrightarrow} \\
& 27 \text { examples }
\end{aligned}
$$

Synergistic action. The cooperative copper salt and topaquinone-like catalysts lower the activation energy enabling high reactivity toward the chemoselective oxidative cross-coupling of primary amines to imines that neither catalyst can accomplish alone.
Martine Largeron*, Maurice-Bernard Fleury

Page No. - Page No.

A Metalloenzyme-Like Catalytic System for the Chemoselective Oxidative Cross-Coupling of Primary Amines to Imines under Ambient Conditions 